\section{„Alfred-Breit-Preis“ der Deutschen Röntgengesellschaft geht an den Charité- Radiologen Bernd Hamm}

Berlin / Hamburg im Mai 2014. Prof. Dr. Bernd Hamm, seit 1993 Direktor der Radiologie der Berliner Charité, erhält den Alfred-Breit-Preis der Deutschen Röntgengesellschaft. Prof. Dr. Hamm empfängt den Preis für seine Verdienste um die experimentelle und klinische Erforschung von Tumoren des Abdomens und des Beckens.

Benannt ist der Preis nach dem Strahlentherapeuten Professor Dr. Alfred Breit, ei- nem der Wegbereiter der Krebsbehandlung durch Bestrahlung (Radio-Onkologie). Der Preis wird seit 2012 vergeben. Er würdigt Arbeiten und Entwicklungen, die aus dem Bereich der radiologischen Forschung kommen und erkennbar zu Fortschritten in der Krebstherapie beitragen können. Gestiftet wurde der mit 20.000 Euro dotierte Preis vom Namensgeber persönlich. Alfred Breit verstarb im Jahr 2011.

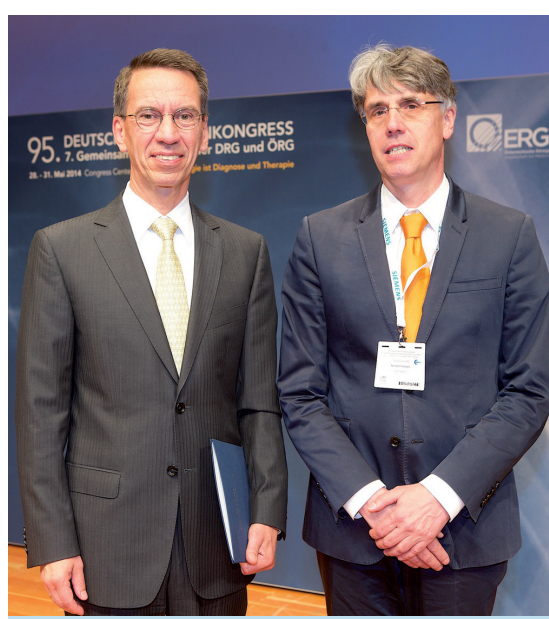

Prof. Dr. Bernd Hamm mit DRG-Präsident Prof. Dr Norbert Hosten. 